a review of the evidence and an extensive consultation process, the WHO recommendation were endorsed by the FFPRHC.

Different rules for pills containing $20 \mu \mathrm{g}$ or $30 \mu \mathrm{g}$ ethinylestradiol are appropriate to minimise intervention for the majority of women without risking contraceptive efficacy.

The risk of pregnancy is greatest when pills are missed either side of the pill-free interval (PFI) and the recommendations in our statement ${ }^{1}$ provide precautionary measures when the PFI is extended to 9 days or more.

We believe that the CEU statement is evidence-based and should facilitate the management of women who miss pills.

Susan Brechin, MRCOG, MFFP

Co-ordinator of the FFPRHC Clinical Effectiveness Unit, Aberdeen Maternity Hospital, Aberdeen,UK.E-mail: sue.brechin@abdn.ac.uk

$1 \quad$ Faculty of Family Planning and Reproductive Health Car Clinical Efrectiveness Unit. Faculty Statement from the CEU on a New Publication: WHO Selected Practice pills: new recos for Contraceptive Use Update. Missed pills: new recommenda
Care 2005; 32: $153-155$.

2 World Health Organization (WHO). Selected Practice Recommendations for Contraceptive Use (2nd edn). Geneva, Switzerland: WHO, 2004. http://www.who.int/ reproductive-

\section{fpa leaflet on the combined pill}

John Guillebaud provides comment about fpa's new leaflet on the combined pill entitled Your Guide to the Combined Pill and 'Missed Pill' Guidance that relates to its content and development.

fpa is the leading sexual health charity in the UK, providing a national information service to the public. fpa helpline and information services respond to more than 100000 enquiries annually and provide more than 10 million leaflets a year to support women's and men's information needs and enable them to make good, confident choices about contraception and other areas of sexual health.

All fpa leaflets contain, where possible, evidence-based information or agreed curren practice and consensus opinion. It is vital that fpa information 'mirrors' evidence-based guidance to ensure that information is harmonised for both professionals and the public. All fpa leaflets are subject to a robust consultation process that involves input from a number of experts in the field, which includes the FFPRHC, to ensure medical accuracy. It also includes consumer testing of the leaflet format and content with the intended audience to ensure it is appropriate and accessible.

The medical information in this new leaflet is based on WHO Medical Eligibility Criteria for Contraceptive Use. ${ }^{1}$ Information about what to do if women miss pills or start a packet late is based on WHO Selected Practice Recommendations for Contraceptive Use, ${ }^{2}$ which has been endorsed by the FFPRHC. fpa's new leaflet on combined oral contraception and the Faculty advice on 'missed pills' were published simultaneously to ensure women and professionals received this new information at the same time.

John Guillebaud questions and disagrees with the new Faculty advice on 'missed pills': as such he takes issue with the new fpa leaflet, which contains the same information. Individual clinicians may disagree with guidelines and may choose to provide alternative advice to their clients, but they need to be clear why their advice is different from consensus practice and be prepared to defend it with women. fpa has the responsibility to ensure it provides information based on evidence or consensus opinion and to produce it in a way that is effective for consumers not professionals. fpa contraceptive leaflets are not product leaflets nor are they teaching tools for professionals: instead they are produced for women choosing and using contraception.
Importantly, they provide 'back-up' information to support practitioners' verbal advice, but they are not intended to replace it.

In reality, women want to feel confident about using the pill, they want to know what to do if they miss pills, start a packet late, become ill, or take concomitant medicines that may affect pill efficacy. This new advice provides for the first time the possibility for consistent information to be given in a way that is understandable and easy to follow. We now all have a responsibility to promote this and ensure it is known about. To do this demands improved understanding and listening by professionals about the issues that worry women about oral contraception and the confusion that exists around taking it correctly.

Toni Belfield, BSc, FRSH

Director of Information, fpa, 2-12 Pentonville Road,London N1 9FP, UK. E-mail: tonib@ fpa.org.uk

References
World Health Organization (WHO). Medical Eligibility Criteria for Contraceptive Use (3rd edn). Geneva health/publications/MEC_3/index.ht.

World Health Organization (WHO). Selected Practice Switzerland: WHO, 2004. http://www.who. int/ reproductivehealth/publications/rhr_02_7/index.htm.

\section{CEU statement on missed pills}

There seem to be several seemingly contradictory statements made within the 'Faculty Statement from the CEU on a New Publication: WHO Selected Practice Recommendations for Contraceptive Use Update. Missed pills: new recommendations'1 with which we are having some difficulty.

If: "Seven consecutive pills are sufficient to inhibit ovulation. The remaining COCs in a pack maintain anovulation in the vast majority of cycles ... Seven consecutive pills are regularly missed in the pill-free interval without losing contraceptive protection."

And if: "The FFPRHC considers that if a woman has missed more than seven consecutive pills, then she has stopped using COC, and the 'missed pill rules' cannot be applied".

How can: Missed ONE or TWO pills - "She does not need any additional contraceptive protection" possibly apply if the two missed pills were at one side of the pill-free interval (PFI)?

Or, how can: Missed THREE or more pills "She should also use condoms or abstain from sex until she has taken pills for 7 days in a row" possibly apply if she has already taken the "seven consecutive pills [which] are sufficient to inhibit ovulation" and has not missed the more than seven which are quoted above as being necessary to lose protection?

Are we alone in translating this as: It's OK to have a PFI of 9 days, don't worry about it, but it' not OK to have a 3-day break in the middle of the pack?

We know we're not alone: many people have asked us to explain it to them and we cannot.

We are all for simplifying things: "Field experience shows a need for simple, harmonised guidance". So, why complicate matters even further by giving two sets of rules for two sets of pills? Wouldn't it have been simpler to go with the lowest common denominator, however irrational.

And then there's the evidence. Several studies have looked at follicular development following extension of the PFI to 9 or 10 days and have found it to be significant; more so in $20 \mu \mathrm{g}$ than in 30 or $35 \mu \mathrm{g}$ ethinylestradiol formulations.

Mishell ${ }^{2}$ quite categorically states that there is an increased risk of pregnancy if the PFI is prolonged to 9 days, quoting Creinin et al. ${ }^{3}$ who found that extending the hormone-free interval from 7 to 9 days with two low-dose formulations resulted in some women having elevated circulating endogenous progesterone levels, providing evidence of luteal activity. These findings would support a reduction in the 7 day PI rather than permitting any extension. We would welcome further enlightenment.

Barbara A Hollingworth, DRCOG, FFFP Consultant and Lead Clinician in Family Planning and Reproductive Health, Redbridge and Havering PCTs, Essex, UK. E-mail. bah@lupins.plus.com

\section{Caroline Marfleet, MB BS, FFFP}

Consultant in Family Planning and Reproductive

Health, Colchester General Hospital, Turner Road, Colchester CO4 5LJ UK. E-mail: marfleets@doctors.org.uk

References
$1 \quad$ Faculty of Family Planning and Reproductive Health Care Clinical Effectiveness Unit. Faculty Statement from the CEU on a New Publication: WHO Selected Practice Recommendations for Contraceptive Use Update. Missed pills: new recommendat
Care 2005; 32: 153-155

2 Mishell DR. Rationale for decreasing the number of days of the hormone-free interval with use of low-dose oral 304-305.

Creinin MD, Lippman JS, Eder BE, Godwin AJ, Olson W. The effect of extending the pill-free interval on follicula activity: triphasic norgestimate/35 micro $g$ ethinyl estradio versus monophasic levonorgestrel/20 micro $g$ ethinyl
estradiol.Contraception 2002; 66: 147-152.

\section{Missed pills}

I am writing on behalf of GPs and nurses at Leeds Student Medical Practice - a practice serving the University here, and hence with $30000+$ patient ery busy with contraceptive issues.

We welcome your missed pills guidelines ${ }^{1}$ and were hoping to use them as a definitive guide. However, we are confused.

The advice re three or more $30 \mu \mathrm{g}$ pills or two or more $20 \mu \mathrm{g}$ pills missed mentions using emergency contraception (EC) if necessary in the first week. It is not mentioned in the second or third week. Does this mean that EC is not required for up to seven pills missed in these weeks? (NB The article states $>7$ pills missed cannot use missed-pill guidelines.) This would seem to make some sense on the basis that it takes $>7$ missed pills before ovulation may occur

If that is the case, then why is the 7-day rule suggested for missed pills in these weeks?

Or should we be giving EC if unprotected sex has occurred and three or more $30 \mu \mathrm{g}$ pills or two or more $20 \mu \mathrm{g}$ pills have been missed in the second or third week, as is our current practice?

We would value your help and clarification please.

Debbie Smith, MRCGP, DFFP

Leeds Student Medical Practice, Leeds University, Leeds, UK. E-mail: deborah.smith (a)nhs.net

Reference
$1 \quad$ Faculty of Family Planning and Reproductive Health Care Clinical Effectiveness Unit. Faculty Statement from the CEU on a New Publication: WHO Selected Practice
Recommendations for Contraceptive Use Update. Missed Recommendations for Contraceptive Use Update. Missed pills: new recommenda
Care 2005; 32: $153-155$.

Reply

Thank you for the opportunity to respond to this common concern, which has been raised about the need for emergency contraception (EC) when combined oral contraceptive pills are missed. The $\mathrm{CEU}$ and Clinical Effectiveness Committee support the new WHO guidelines for missed combined oral contraceptive pills (COCs) that EC need only be considered when pills are missed in Week $1.1,2$

When pills are missed in Week 1 the pill-free interval (PFI) has already effectively been extended by the time a woman presents. Thus, she is potentially at risk of ovulation and pregnancy if she has had unprotected sex in the pill-free week or in the first week of pill taking. When pills are missed in Weeks 2 or 3 , advice can be given to allow the woman to avoid extending the PFI (by 